\title{
ANALISIS KEPATUHAN BIDAN PRAKTIK MANDIRI DALAM MERUJUK PERSALINAN KE PUSKESMAS SEBAGAI JEJARING JAMINAN KESEHATAN NASIONAL DI KABUPATEN GROBOGAN
}

\author{
Festy Mahanani Mulyaningrum ${ }^{1 \cdot}$ Wahyu Dewi Hapsari ${ }^{2}$ \\ e-mail:megawae39@yahoo.co.id \\ ${ }^{1,2}$ STIKES An Nur Purwodadi Prodi DIII Kebidanan, Kabupaten Purwodadi
}

\begin{abstract}
Abstrak
AKI merupakan indikator yang digunakan untuk mengetahui besaran masalah kesehatan ibu. Kabupaten Grobogan menduduki peringkat ketiga dengan AKI tertinggi di Jawa Tengah. Kematian ibu dan bayi sering terjadi akibat penanganan yang dilakukan bidan desa kurang berstandar, maka intervensi ditekankan pada kegiatan pertolongan persalinan yang aman oleh tenaga kesehatan terlatih. Penelitian ini bertujuan untuk menganalisis kepatuhan bidan praktik mandiri dalam merujuk persalinan ke Puskesmas sebagai jejaring jaminan kesehatan nasional di Kabupaten Grobogan. Jenis penelitian ini adalah penelitian kuantitatif dengan survei analitik. Populasi dalam penelitian ini adalah 169 BPM di Kabupaten Grobogan. Pengumpulan data menggunakan kuesioner dan analisis data dengan regresi logistik ganda. Hasil penelitian menunjukkan Karakteristik umur responden lebih banyak yang berumur $\geq 36$ tahun atau dewasa penuh (55,7\%), berpendidikan D3 Kebidanan (92,9\%), masa kerja lama $\geq 5$ tahun $(92,9 \%)$. Tingkat pengetahuan responden $64,3 \%$ sudah baik, sikap responden 58,6\% baik, peraturan Pemerintah $87,1 \%$ sudah baik dalam mendukung, dan tingkat motivasi responden $88,6 \%$ tinggi. Ada pengaruh secara bersama antara sikap dan motivasi terhadap kepatuhan BPM dalam merujuk persalinan ke Puskesmas sebagai jejaring Jaminan Kesehatan Nasional. Faktor motivasi merupakan faktor yang paling dominan berpengaruh terhadap kepatuhan BPM dalam merujuk persalinan ke Puskesmas sebagai jejaring JKN di Kabupaten Grobogan.
\end{abstract}

Kata Kunci $\quad$ : Pengetahuan, Sikap, dan Diet Seimbang

\section{Pendahuluan}

Menurut data Survei Demografi Kesehatan Indonesia (SDKI) AKI di Indonesia pada tahun 2012 mencapai 359/100.000 Kelahiran Hidup (KH), sedangkan AKB menjadi 32/1.000 KH. Angka tersebut masih jauh dari target MDG's tahun 2015 yaitu AKI turun menjadi 102/100.000 KH dan AKB 23/1.000 KH. Penyebab kematian ibu tersebut dikarenakan adanya lain-lain (42,33\%), hipertensi $(26,44 \% \%)$, perdarahan $(22,93 \%)$, gangguan sistem peredaran darah $(4,64 \%)$ dan infeksi (3,66\%). Karena kejadian komplikasi sulit diduga sebelumnya, maka harus tersedia fasilitas dan tenaga kesehatan yang mampu memberikan pelayanan maternal neonatal yang berkualitas. ${ }^{[1,2]}$

AKI di Provinsi Jawa Tengah selama tahun 2012 berdasarkan laporan dari kabupaten atau Kota sebesar 116,34/$100.000 \mathrm{KH}$ meningkat 118,62/100.000 KH di tahun 2013 dan meningkat lagi menjadi $126,55 / 100.000 \mathrm{KH}$ di tahun 2014. AKI dari 35 daerah di Jawa Tengah yang memiliki
AKI cukup tinggi antara lain Brebes yang tercatat 73 kasus diikuti Tegal 47 kasus, Grobogan 43 kasus, Pemalang 40 kasus, dan Pekalongan 39 kasus pada tahun 2014. Hal ini membuat Kabupaten Grobogan menduduki peringkat ketiga dengan AKI tertinggi di Jawa Tengah. Menurut data kematian maternal dan neonatal di Dinas Kesehatan Kabupaten Grobogan jumlah AKI tahun 2013 mencapai 101,10/100.000 $\mathrm{KH}$ dan AKB 14,14/1000 KH dan meningkat di tahun 2014 menjadi 188,69/$100.000 \mathrm{KH}$ begitu juga dengan AKB $17,82 / 1000 \mathrm{KH}$. Kematian ibu dan bayi sering terjadi akibat penanganan yang dilakukan bidan desa kurang berstandar, maka intervensi ditekankan pada kegiatan pertolongan persalinan yang aman oleh tenaga kesehatan terlatih. Melalui pertolongan yang baik dan benar, diharapkan komplikasi akibat salah penanganan bisa dicegah, mengetahui dengan cepat komplikasi yang timbul dan dengan segera memberikan pertolongan termasuk merujuk bila diperlukan. ${ }^{[3,4,5]}$ 
Berdasarkan tingginya AKI di Kabupaten Grobogan yang semakin meningkat, Kepala Dinas Kesehatan Kabupaten Grobogan membuat kebijakan tentang persalinan yang selama ini dibantu oleh bidan terdekat dan terpercaya, untuk ke depan akan dirujuk atau dilayani oleh Puskesmas terdekat dengan dokter dan perlengkapan medis secara maksimal. Pelayanan Puskesmas buka 1 x 24 jam setiap harinya dengan harapan bisa mengurangi angka kematian ibu dan bayi. ${ }^{[6,7]}$

Memperoleh pelayanan maternal neonatal yang aman dan bermutu terkadang membutuhkan dana yang tidak sedikit untuk membayar jasa pelayanan sehingga tidak semua orang mampu untuk mendapatkan pelayanan kesehatan tersebut. Untuk membantu biaya persalinan penduduk, pada tahun 2004 dikeluarkan Undang-Undang Nomor 4 Tahun 2004 tentang Sistem Jaminan Sosial Nasional (SJSN). UndangUndang ini mengamanatkan bahwa program jaminan sosial wajib bagi seluruh penduduk termasuk program Jaminan Kesehatan melalui suatu Badan Penyelenggaraan Jaminan Sosial (BPJS). Program Jaminan Kesehatan yang diselenggarakan oleh BPJS Kesehatan implementasinya telah dimulai sejak 1 Januari 2014 yang disebut program Jaminan Kesehatan Nasional (JKN) yang bertujuan agar seluruh penduduk Indonesia terlindungi dalam sistem asuransi sehingga mereka dapat memenuhi kebutuhan dasar kesehatan serta pelayanan kesehatan maternal neonatal.

Pada penyelenggaraan JKN, Bidan sebagai pelayanan kebidanan merupakan jejaring Fasilitas Kesehatan Tingkat Pertama (FKTP) yang telah bekerjasama dengan BPJS Kesehatan. Dalam hal klaim yang dilakukan melalui FKTP milik Pemerintah Daerah, setelah dibayar oleh BPJS, FKTP milik Pemerintah Daerah segera membayarkan secara utuh kepada Bidan jejaring sesuai dengan besaran klaim terhadap pelayanan yang diberikan. Proses klaim JKN dipengaruhi oleh kelengkapan dan kesesuaian pengisian format serta banyaknya klaim yang diajukan.

Berdasarkan studi pendahuluan terdapat 169 BPM di Kabupaten Grobogan di tahun 2016. Dengan adanya AKI yang meningkat pihak Dinas Kesehatan Kabupaten (DKK) Grobogan membuat kebijakan baru berupa himbauan agar persalinan ke depan akan dirujuk atau dilayani oleh Puskesmas terdekat dengan dokter dan perlengkapan medis secara maksimal. Hal ini berkaitan erat dengan program JKN yang mengharapkan BPM menjalin jejaring dengan FKTP. Kebijakan tersebut telah disosialisasikan secara lisan melalui pertemuan di DKK Grobogan yang dihadiri Kepala Puskesmas wilayah kerja Kabupaten Grobogan dan Ketua Ikatan Bidan Indonesia (IBI) ranting maupun cabang Kabupaten Grobogan. Kemudian kebijakan tersebut di uji cobakan di wilayah kerja Puskesmas Karangrayung I Kabupaten Grobogan sejak bulan November 2015. Hasil dari pelaksanaan kebijakan tersebut dikatakan berhasil seperti yang diutarakan oleh Kepala Puskesmas Karangrayung I saat pertemuan selanjutnya pada bulan Januari 2016, bahwa tidak ada kematian ibu sampai bulan 22 April 2016. Sampai kini Peraturan Bupati terkait kebijakan tersebut masih dalam tahap proses.

IBI sangat mendukung keikutsertaan Bidan Prakktik Mandiri (BPM) dalam program JKN, tetapi beberapa BPM tidak mendukung. Hasil wawancara dengan 5 BPM penulis mengambil kesimpulan bahwa perilaku BPM yang memilih tidak ikut serta dalam jejaring JKN tersebut tampak dari mulai adanya stimulus berupa kebijakan baru tentang persalinan akan dirujuk atau dilayani oleh Puskesmas terdekat. Kemudian diterima oleh organisme (BPM), yang mengetahui adanya kebijakan baru tersebut memberikan respon berupa keengganan BPM ikut serta jejaring JKN. Persoalannya dalam kerja sama dengan jejaring FKTP dalam hal ini Puskesmas itu tidak ada ketentuan resmi tentang pembagian tarif serta terkesan lama dalam proses pengklaimannya. Sebagian bidan menerima penuh tarif layanan sesuai standar, tetapi ada pula yang dipotong hingga beberapa persen. Ketidakjelasan aturan itu membuat banyak BPM enggan ikut serta dalam jejaring JKN. ${ }^{[8]}$ 


\section{Metodologi}

Jenis penelitian ini adalah penelitian kuantitatif dengan desain penelitian observasional dengan menggunakan metode penelitian survei analitik. Populasi dalam penelitian ini adalah BPM di Kabupaten Grobogan dengan jumlah 169 orang. Teknik pengumpulan data menggunakan kuesioner yang telah diuji validitas dan reliabilitasnya dengan analisis korelasi product moment $(\mathrm{p}$ value $<0,05$ ).

Analisa data menggunakan chi-square dan analisis regresi logistik berganda.

\section{Hasil Dan Pembahasan}

Tabel 1 Hubungan antara pengetahuan dengan kepatuhan BPM dalam merujuk persalinan ke Puskesmas sebagai jejaring JKN di Kabupaten Grobogan.

\begin{tabular}{|c|c|c|c|c|c|c|c|}
\hline \multirow{3}{*}{$\begin{array}{l}\text { Peng } \\
\text { etah } \\
\text { uan }\end{array}$} & \multicolumn{4}{|c|}{ Kepatuhan BPM } & & & \multirow{3}{*}{$\begin{array}{c}\mathbf{p} \\
\text { value }\end{array}$} \\
\hline & \multicolumn{2}{|c|}{$\begin{array}{c}\text { Kuran } \\
\text { g Patuh }\end{array}$} & \multicolumn{2}{|c|}{ Patuh } & \multicolumn{2}{|c|}{ Total } & \\
\hline & f & $\%$ & f & $\%$ & $\mathbf{f}$ & $\%$ & \\
\hline $\begin{array}{c}\text { Kura } \\
\text { ng }\end{array}$ & 2 & $\begin{array}{c}13 \\
3 \\
\%\end{array}$ & $\begin{array}{l}2 \\
3\end{array}$ & $\begin{array}{c}41, \\
8 \\
\%\end{array}$ & $\begin{array}{l}2 \\
5\end{array}$ & $\begin{array}{c}35 \\
7 \\
\%\end{array}$ & 0,041 \\
\hline Baik & $\begin{array}{l}1 \\
3\end{array}$ & $\begin{array}{c}86 \\
7 \\
\%\end{array}$ & $\begin{array}{l}3 \\
2\end{array}$ & $\begin{array}{c}58, \\
2 \\
\%\end{array}$ & $\begin{array}{l}4 \\
5\end{array}$ & $\begin{array}{c}64, \\
3 \\
\%\end{array}$ & \\
\hline
\end{tabular}

Berdasarkan hasil penelitian pada diatas dapat diketahui bahwa dari 55 kelompok responden BPM yang patuh terdapat 32 BPM $(58,2 \%)$ yang berpengetahuan baik, dan 23 BPM (41,8\%) berpengetahuan kurang baik. Hal itu menunjukkan bahwa kebanyakan BPM yang patuh lebih banyak memiliki pengetahuan baik tentang kebijakan Pemerintah Kabupaten Grobogan di era JKN.

Dari uji statistik chi-square kedua variabel ini menunjukkan adanya hubungan bermakna antara pengetahuan dengan kepatuhan BPM dalam merujuk persalinan ke Puskesmas sebagai jejaring JKN di Kabupaten Grobogan ditunjukkan dengan nilai $\mathrm{p}=0,041($ dimana $\mathrm{p}<0,05)$.
Tabel 2 Hubungan antara sikap dengan kepatuhan BPM dalam merujuk persalinan ke Puskesmas sebagai jejaring JKN di Kabupaten Grobogan.

\begin{tabular}{|c|c|c|c|c|c|c|c|}
\hline \multirow{3}{*}{$\begin{array}{l}\text { Sik } \\
\text { ap }\end{array}$} & \multicolumn{4}{|c|}{ Kepatuhan BPM } & \multicolumn{2}{|c|}{ Total } & \multirow{3}{*}{$\begin{array}{c}\text { p } \\
\text { val } \\
\text { ue }\end{array}$} \\
\hline & \multicolumn{2}{|c|}{$\begin{array}{c}\text { Kurang } \\
\text { Patuh }\end{array}$} & \multicolumn{2}{|c|}{ Patuh } & $\mathbf{f}$ & $\%$ & \\
\hline & $\mathbf{f}$ & $\%$ & $\mathbf{f}$ & $\%$ & & & \\
\hline Kur & 12 & 80 & 1 & 30,9 & 2 & 41,4 & \\
\hline ang & & $\%$ & 7 & $\%$ & 9 & $\%$ & 0,0 \\
\hline Bai & 3 & 20 & 3 & 69,1 & 4 & 58,6 & 01 \\
\hline $\mathrm{k}$ & & $\%$ & 8 & $\%$ & 1 & $\%$ & \\
\hline
\end{tabular}

Berdasarkan hasil penelitian pada diatas dapat diketahui bahwa bahwa bahwa dari 55 kelompok responden BPM yang patuh terdapat 38 BPM $(69,1 \%)$ yang bersikap baik, dan 17 BPM (30,9\%) bersikap kurang baik. Hal ini menunjukkan bahwa kebanyakan BPM yang patuh lebih banyak bersikap baik terhadap kebijakan Pemerintah Kabupaten Grobogan di era JKN.

Dari uji statistik chi-square kedua variabel ini menunjukkan adanya hubungan bermakna antara sikap dengan kepatuhan BPM dalam merujuk persalinan ke Puskesmas sebagai jejaring JKN di Kabupaten Grobogan ditunjukkan dengan nilai $\mathrm{p}=0,001$ (dimana $\mathrm{p}<0,05)$.

Tabel 3. Hubungan antara peraturan Pemerintah dengan kepatuhan BPM dalam merujuk persalinan ke Puskesmas sebagai jejaring JKN di Kabupaten Grobogan.

\begin{tabular}{|c|c|c|c|c|c|c|c|}
\hline \multirow{3}{*}{$\begin{array}{c}\text { Perat } \\
\text { uran } \\
\text { Peme } \\
\text { rinta } \\
\text { h }\end{array}$} & \multicolumn{4}{|c|}{$\begin{array}{c}\text { Kepatuhan } \\
\text { BPM }\end{array}$} & \multicolumn{2}{|c|}{ Total } & \multirow{3}{*}{$\begin{array}{c}p \\
\text { value }\end{array}$} \\
\hline & \multicolumn{2}{|c|}{$\begin{array}{c}\text { Kura } \\
\text { ng } \\
\text { Patuh }\end{array}$} & \multicolumn{2}{|c|}{ Patuh } & f & $\%$ & \\
\hline & $\mathrm{f}$ & $\%$ & $\mathrm{f}$ & $\%$ & & & \\
\hline $\begin{array}{c}\text { Kuran } \\
\mathrm{g}\end{array}$ & 6 & $\begin{array}{l}4 \\
0\end{array}$ & 3 & $\begin{array}{c}5,5 \\
\%\end{array}$ & 9 & $\begin{array}{l}12, \\
9 \%\end{array}$ & \\
\hline Baik & 9 & $\begin{array}{c}\% \\
6 \\
0 \\
\%\end{array}$ & $\begin{array}{l}5 \\
2\end{array}$ & $\begin{array}{l}94, \\
5 \%\end{array}$ & $\begin{array}{l}6 \\
1\end{array}$ & $\begin{array}{l}87, \\
1 \%\end{array}$ & 0,002 \\
\hline
\end{tabular}

Berdasarkan hasil penelitian pada diatas dapat diketahui bahwa bahwa dari 55 kelompok responden BPM yang patuh terdapat 52 BPM (94,5\%) yang menganggap Peraturan Pemerintah mendukung dengan baik, dan 3 BPM (5,5\%) yang menganggap 
peraturan Pemerintah kurang mendukung himbauan dari Pemerintah Kabupaten Grobogan di era JKN. Hal ini menunjukkan bahwa kebanyakan BPM yang patuh lebih banyak menganggap Peraturan Pemerintah mendukung dengan baik kebijakan dari Pemerintah Kabupaten Grobogan di era JKN.

Dari uji statistik chi-square kedua variabel ini menunjukkan adanya hubungan bermakna antara peraturan Pemerintah dengan kepatuhan BPM dalam merujuk persalinan ke Puskesmas sebagai jejaring JKN di Kabupaten Grobogan ditunjukkan dengan nilai $\mathrm{p}=0,002($ dimana $\mathrm{p}<0,05)$.

Tabel 4 Hubungan antara motivasi dengan kepatuhan BPM dalam merujuk persalinan ke Puskesmas sebagai jejaring JKN di Kabupaten Grobogan di Kabupaten Grobogan.

\begin{tabular}{|c|c|c|c|c|c|c|c|}
\hline \multirow{3}{*}{$\begin{array}{c}\text { Moti } \\
\text { vasi }\end{array}$} & \multicolumn{4}{|c|}{ Kepatuhan BPM } & \multicolumn{2}{|c|}{ Total } & \multirow{3}{*}{$\begin{array}{c}p \\
\text { value }\end{array}$} \\
\hline & \multicolumn{2}{|c|}{$\begin{array}{c}\text { Kuran } \\
\text { g } \\
\text { Patuh }\end{array}$} & \multicolumn{2}{|c|}{ Patuh } & $\mathbf{f}$ & $\%$ & \\
\hline & $\mathbf{F}$ & $\%$ & $\mathbf{F}$ & $\%$ & & & \\
\hline $\begin{array}{c}\text { Rend } \\
\text { ah }\end{array}$ & 5 & $\begin{array}{l}33, \\
3 \%\end{array}$ & 3 & $\begin{array}{c}5,5 \\
\%\end{array}$ & 8 & $\begin{array}{c}11 \\
4 \\
\%\end{array}$ & \\
\hline $\begin{array}{c}\text { Tingg } \\
\mathrm{i}\end{array}$ & $\begin{array}{l}1 \\
0\end{array}$ & $\begin{array}{l}66, \\
7 \%\end{array}$ & $\begin{array}{l}5 \\
2\end{array}$ & $\begin{array}{l}94, \\
5 \%\end{array}$ & $\begin{array}{l}6 \\
2\end{array}$ & $\begin{array}{c}88, \\
6 \\
\%\end{array}$ & 011 \\
\hline
\end{tabular}

Berdasarkan hasil penelitian pada diatas dapat diketahui bahwa dari 55 kelompok responden BPM yang patuh terdapat 52 BPM $(94,5 \%)$ yang mempunyai motivasi tinggi, dan 3 BPM $(5,5 \%)$ yang mempunyai motivasi rendah. Hal ini menunjukkan bahwa kebanyakan BPM patuh lebih banyak memiliki motivasi tinggi daripada yang motivasinya kurang terhadap kebijakan Pemerintah Kabupaten Grobogan di era JKN. ${ }^{[11,13]}$

Dari uji statistik chi-square kedua variabel ini menunjukkan adanya hubungan bermakna antara motivasi dengan kepatuhan BPM dalam merujuk persalinan ke Puskesmas sebagai jejaring JKN di Kabupaten Grobogan ditunjukkan dengan nilai $\mathrm{p}=0,011($ dimana $\mathrm{p}<0,05)$.
Tabel 5 Hasil analisis regresi multivariat dengan metode enter variabel bebas terhadap variabel terikat.

\begin{tabular}{cccc}
\hline Variabel & Koefisien & $\begin{array}{c}\text { Nilai } \\
\mathbf{p}\end{array}$ & OR (IK95\%) \\
\hline Sikap & 2,492 & 0,003 & $\begin{array}{c}12,082(2,367- \\
61,674)\end{array}$ \\
Motivasi & 2,635 & 0,010 & $\begin{array}{c}13,943(1,901- \\
102,287)\end{array}$ \\
\hline
\end{tabular}

Berdasarkan hasil penelitian pada diatas dapat diketahui bahwa secara bersama-sama sikap, motivasi yang berpengaruh terhadap kepatuhan BPM dalam merujuk persalinan ke Puskesmas sebagai jejaring JKN di Kabupaten Grobogan karena $\mathrm{p}<0,05$.

Berdasarkan nilai $\operatorname{Exp}(B)$ pada hasil analisis di atas dapat dijelaskan bahwa variabel suatu motivasi yang tinggi berpengaruh terhadap kepatuhan BPM sebesar 13,943 kali lebih besar dalam merujuk persalinan ke Puskesmas sebagai jejaring JKN di Kabupaten Grobogan. Dalam hal ini variabel motivasi merupakan pengaruh terbesar terhadap kepatuhan BPM diantara variabel yang lain.

\section{Kesimpulan}

Ada pengaruh secara bersama antara sikap dan motivasi terhadap kepatuhan Bidan praktik mandiri dalam merujuk persalinan ke Puskesmas sebagai jejaring Jaminan Kesehatan Nasional. Faktor motivasi merupakan faktor yang paling dominan berpengaruh terhadap kepatuhan BPM dalam merujuk persalinan ke Puskesmas sebagai jejaring JKN di Kabupaten Grobogan.

\section{Daftar Pustaka}

[1] Dinas Kesehatan Propinsi Jawa Tengah. Profil Kesehatan Propinsi Jawa Tengah Tahun 2013. Semarang: Dinkes; 2013.

[2] Fahmi, Zulkifli. Persalinan Diusulkan di Puskesmas Saja. Semarang: Suara Merdeka; 2015.

[3] Alfariz. Dinkes Jateng Tekan Jumlah Angka Kematian Ibu dan Bayi, Semarang: Berita Jateng; 2015. 
[4] Fahmi, Zulkifli. Asklindo Siap Dukung Kebijakan Pemerintah. Semarang: Suara Merdeka; 2015.

[5]DKK Grobogan. Data Kematian Maternal Neonatal Bulan Januari Desember Tahun 2012 - 2014. Grobogan: 2014.

[6] Suraji. Pelayanan Persalinan dan BPJS. Grobogan: DKK Grobogan; 2014.

[7] Sholehah, Fitria Maratus. Kebijakan Hukum dalam Kesehatan Kewajiban Bersalin di Puskesmas untuk Wilayah Kabupaten Grobogan. Program Studi D-IV Kebidanan. Semarang: STIKES Karya Husada; 2015.

[8] Ratama, Sefisa Andri. Analisis Faktor yang Mempengaruhi Keikutsertaan Bidan Praktik Swasta (BPS) dalam Program Jaminan Persalinan (JAMPERSAL) di Kota Surabaya (Tesis). Semarang: Program Studi Manajemen Program Pasca Sarjana Universitas Diponegoro; 2012.

[9] Green, L. Health Promotion Planning an Educational and Enviromental Approach. 2 ed. USA: Mayfield Publishing Company; 2000.

[10] Notoatmodjo, S. Ilmu Perilaku Kesehatan. Jakarta: Rineka Cipta; 2010.

[11] Retnaningsi, Ekowati Nuryanto. Kepatuhan Tenaga Kesehatan terhadap Standar Operasional Prosedur Pertolongan Persalinan untuk Menurunkan Angka Kematian Ibu Di Provinsi Sumatera Selatan; 2012.

[12] Mukwanto, KP, Ngoma CM, Maimbalwa. Compliance with Infection Prevention Guidelines By Health Care Workers At Ronald Ross General Hospital Mufulira Distric. Med Journal of Zambia; 2010.

[13] Palutturi, Sukri. Nurhayani. Mandak, Nurhamsa. Determinan Kinerja Bidan di Puskesmas Tahun 2006. Jurnal Manajemen Pelayanan Kesehatan. 2007. 